\title{
Effects of supplementing yeast culture to diets differing in starch content on performance and feeding behavior of dairy cows
}

\author{
A. L. G. Dias, ${ }^{*} \dagger$ J. A. Freitas, ${ }^{* 1}$ B. Micai, ${ }^{*}$ R. A. Azevedo, ${ }^{*}$ L. F. Greco, ${ }^{*}$ and J. E. P. Santos ${ }^{*} \ddagger^{2}$ \\ *Department of Animal Sciences, University of Florida, Gainesville 32611 \\ †Department of Animal Sciences, State University of Maringá, PR, Brazil, 87020-900 \\ ‡DH Barron Reproductive and Perinatal Biology Research Program, University of Florida, Gainesville 32611
}

\begin{abstract}
The objectives were to evaluate the effects of a culture of Saccharomyces cerevisiae (YC) on lactation performance of cows fed diets differing in starch content. Fifty-six Holstein cows at $42 \mathrm{~d}$ postpartum were blocked by parity and milk production and randomly assigned to 1 of 4 treatments, low starch (23\% diet DM) and no YC (LS-control), low starch and $15 \mathrm{~g} / \mathrm{d}$ of YC (LS-YC), high starch (29\% diet DM) and no YC (HS-control), and high starch and $15 \mathrm{~g} / \mathrm{d}$ of YC (HS-YC). The experiment lasted 14 wk. Blood was sampled twice weekly during the first 5 wk in the experiment. Feeding behavior was evaluated in 2 consecutive days when cows were $33 \mathrm{~d}$ in the experiment. On d 92 in the experiment, cows were challenged with $3 \mathrm{~kg}$ of corn grain DM immediately before the morning feeding. Blood was sampled in the first $12 \mathrm{~h}$ after the challenge. Rumen fluid was collected $5 \mathrm{~h}$ after the challenge, and $\mathrm{pH}$, ammonia $\mathrm{N}$, short-chain fatty acids, and lactate concentrations were quantified. Lactation performance was measured daily before and after the challenge. Supplementation with YC increased yields of $3.5 \%$ fat-corrected milk and energy-corrected milk by 2.2 and $2.0 \mathrm{~kg} / \mathrm{d}$, and the increments were observed in both low- and high-starch diets. Feeding HS tended to decrease milk fat content $(\mathrm{LS}=3.88$ vs. HS $=$ $3.73 \%$ ), but increased concentration (LS $=2.87$ vs. HS $=3.00 \%)$ and yield ( $\mathrm{LS}=1.11 \mathrm{vs} . \mathrm{HS}=1.20 \mathrm{~kg} / \mathrm{d})$ of milk true protein. Feeding YC increased yields of fat and true protein in milk by 100 and $60 \mathrm{~g} / \mathrm{d}$. Energy balance, body weight, and feed efficiency did not differ with treatments. Feeding HS reduced eating time (LS $=177$ vs. $\mathrm{HS}=159 \mathrm{~min} / 12 \mathrm{~h}$ ) and intermeal interval $(\mathrm{LS}=103$ vs. $\mathrm{HS}=82 \mathrm{~min})$, but tended to increase eating rate $(\mathrm{LS}=139$ vs. HS $=150 \mathrm{~g} / \mathrm{min})$. Interac-
\end{abstract}

Received May 27, 2017.

Accepted September 7, 2017.

${ }^{1}$ Present address: Department of Animal Sciences, Federal University of Paraná, Palotina, PR, Brazil, 85950-000.

${ }^{2}$ Corresponding author: jepsantos@ufl.edu tions were detected between level of starch and $\mathrm{YC}$ for ruminating time, meal duration, and meal size because within LS, feeding YC increased ruminating time 23 $\mathrm{min} / 12 \mathrm{~h}$, but reduced meal duration $6 \mathrm{~min} /$ meal and meal size $0.7 \mathrm{~kg} /$ meal. Concentrations of glucose in plasma increased $(\mathrm{LS}=62.1$ vs. HS $=63.8 \mathrm{mg} / \mathrm{dL})$, whereas those of urea $\mathrm{N}$ decreased $(\mathrm{LS}=10.1$ vs. $\mathrm{HS}=$ $9.4 \mathrm{mg} / \mathrm{dL}$ ) with feeding HS compared with LS in the first $5 \mathrm{wk}$ in the experiment, and the same responses were observed after the challenge with corn grain. After the challenge, rumen $\mathrm{pH}$ was less and short-chain fatty acid concentrations were greater in cows fed HS compared with those fed LS; however, supplementing YC to high-starch diets increased rumen $\mathrm{pH}$ (HS-control = 5.72 vs. HS-YC $=6.12$ ) and reduced concentrations of lactate in rumen fluid (HS-control $=7.72$ vs. HS-YC $=1.33 \mathrm{~m} M$ ) and haptoglobin in plasma $28 \%$. Feeding $\mathrm{YC}$ improved lactation performance irrespective of the level of dietary starch and reduced the risk of subacute rumen acidosis induced by a grain challenge when cows were fed a high-starch ration.

Key words: dairy cow, rumen acidosis, starch, yeast culture

\section{INTRODUCTION}

Saccharomyces cerevisiae-based products are supplemented in diets of dairy cattle because of their effect on DMI, rumen $\mathrm{pH}$, and nutrient digestibility (Callaway and Martin, 1997; Desnoyers et al., 2009; Nocek et al., 2011; AlZahal et al., 2014). These products usually increase yields of milk and milk components (Poppy et al., 2012), or improve efficiency of feed utilization by dairy cows (Schingoethe et al., 2004). Nevertheless, the benefits of feeding yeast culture to lactating dairy cows has been shown to be heterogeneous (Poppy et al., 2012). For instance, when supplemented to diets of lactating dairy cows before 70 DIM, yeast culture improved DMI by approximately $0.6 \mathrm{~kg} / \mathrm{d}$, whereas in experiments in which supplementation occurred in mid to late lactation, DMI decreased approximately $0.8 \mathrm{~kg} / \mathrm{d}$. The decrease in DMI at the same time that production is enhanced likely explains the improvements in feed ef- 
ficiency of mid-lactation cows when supplemented with yeast culture (Schingoethe et al., 2004).

Experiments conducted in vivo and in vitro have shown that yeast cultures are able to stimulate growth of rumen cellulolytic bacteria (Harrison et al., 1988; Callaway and Martin, 1997), which is critical for carbohydrate digestion. Some strains of live S. cerevisiae favor the establishment of fibrolytic bacteria in the digestive tract of gnotobiotically reared lambs, which demonstrated to accelerate microbial activities in the rumen (Chaucheyras-Durand and Fonty, 2001). Desnoyers et al. (2009) reviewed the literature on yeast products and found that $S$. cerevisiae supplementation increased the $\mathrm{OM}$ digestibility in a dose-dependent manner. The positive effect of yeast on OM digestibility decreased as the proportion of concentrate in the diet increased, suggesting that the benefits on OM digestion were dependent on the supply of fiber in the diet. However, one of the documented benefits of live yeast products is the control of rumen acidosis. Cows fed TMR in the feedbunk, but receiving concentrates during milking, showed increased rumen $\mathrm{pH}$ when the diet was supplemented with a live yeast product (Bach et al., 2007). Some of the benefit was attributed to changes in feeding behavior because yeast-supplemented cows had increased meal frequency, which is thought to alleviate the acid load in the rumen. Nevertheless, in vitro experiments have shown that yeast culture can influence microbial populations and favor fibrolytic microorganisms and those considered lactate utilizers (Callaway and Martin, 1997). Nevertheless, shifts in microbial populations in vitro have not always translated into changes in vivo in dairy cows (Mullins et al., 2013). It is possible that the increase in rumen $\mathrm{pH}$ with feeding yeast products results from the combined effect on lactate utilization and changes in feeding behavior that favor a more stable rumen fermentation. It is interesting to note that the benefits of supplementing yeast products on rumen $\mathrm{pH}$ are exacerbated by increased DMI or by feeding more concentrates (Desnoyers et al., 2009). This might explain the benefit of yeast culture supplementation in preventing milk fat depression when cows were challenged with rumen-fermentable starch (Longuski et al., 2009).

Poppy et al. (2012) observed that the effect of yeast culture on DMI and yield of milk components is heterogeneous, and one of the possible factors explaining this variability is the fermentability of the diet. Williams et al. (1991) showed that supplementing a yeast culture increased yield of FCM, but the benefit was greater in the diet with $60 \%$ compared with $50 \%$ concentrate content. Variation in diet fermentability is common, either because purposely formulated, or because of mixing errors on farms. Yeast culture and live yeast products have the ability to minimize fluctuations in rumen $\mathrm{pH}$, which might be more beneficial in diets of increased fermentability. The hypothesis of the current experiment is that yeast culture improves dairy cow performance and the benefits are greater in diets with increased starch content. Therefore, the objectives were to evaluate response to supplemental yeast culture in early lactation Holstein cows when fed diets varying in starch content.

\section{MATERIALS AND METHODS}

All procedures with experimental cows were approved by the University of Florida Institute of Food and Agriculture Science Animal Research Committee under protocol number 007-13ANS.

\section{Cows and Housing}

The experiment was conducted from October of 2013 to January of 2014. Fifty-six early-lactation Holstein cows from the University of Florida Dairy Unit were enrolled in the experiment in 4 weekly cohorts of 4 to 24 cows each. Cows at $32 \pm 11$ DIM were moved to the experimental pens for a 2 -d period to acclimate to individual feeding gates (Calan Broadbent feeding system, American Calan Inc., Northwood, NH). From 34 to 41 DIM, all cows were fed the same TMR which corresponded to the low-starch diet not supplemented with yeast culture. Data collected during this 8-d pretreatment period were used as covariate during statistical analysis. At experiment enrollment, cows averaged $591 \pm 78 \mathrm{~kg}$ of BW, BCS of $2.90 \pm 0.03$, and $41.1 \pm$ $12.0 \mathrm{~kg}$ of $3.5 \%$ FCM. Treatments initiated at $42 \pm 12$ DIM and the experiment ended 14 wk later, when cows averaged $140 \pm 12$ DIM. Therefore, the measurements corresponded to wk 7 to 21 postpartum. Cows were housed in the same freestall barn with sand-bedded stalls, and each cow was randomly assigned to an individual feeding gate for measurements of individual feed intake.

\section{Experimental Design, Treatments, and Feeding}

The experiment followed a randomized complete block design with a $2 \times 2$ factorial arrangement of treatments. Weekly cohort of cows were blocked by parity as primiparous or multiparous and 3.5\% FCM during the 8-d pre-treatment period and, within each block, randomly assigned to 1 of the 4 treatments. Treatments were 2 levels of dietary starch, 23 or $29 \%$ of the diet DM, without or with supplemental yeast culture (YC) resulting in 4 combinations: low starch (LS) and no YC (LS-control); LS with YC (LS-YC); 
high starch (HS) and no YC (HS-control), and HS with YC (HS-YC). Starch in the diet was increased primarily by replacing a portion of the forage with finely ground corn (Table 1). Diets were isonitrogenous, but the caloric density increased slightly with the additional starch in HS. Diets were formulated to meet or exceed the nutrient requirements of cows weighing $600 \mathrm{~kg}$ of BW and producing $40 \mathrm{~kg}$ of $3.5 \% \mathrm{FCM}$ when intake averages $25 \mathrm{~kg} / \mathrm{d}$ (NRC, 2001). The YC was an inactivated dry Saccharomyces cerevisiae cultured in sugar cane derivatives (Rumen Yeast, ICC Brazil, São Paulo, SP, Brazil). The YC product was mixed at 15:85 ratio with finely ground corn and $100 \mathrm{~g}$ of this mixture was top dressed daily to cows fed the LS-YC and HS$\mathrm{YC}$ to result in $15 \mathrm{~g} / \mathrm{cow}$ per $\mathrm{d}$ of $\mathrm{YC}$. The control diet was top dressed with $100 \mathrm{~g} / \mathrm{d}$ of finely ground corn.

Cows were fed twice daily, approximately at $0730 \mathrm{~h}$ and again at $1300 \mathrm{~h}$. The amounts of feed offered to individual cows were adjusted daily to result in at least $5 \%$ refusals, which were weighed once daily at $0700 \mathrm{~h}$, before the morning feeding. Twice weekly, diets and ingredients were sampled, dried at $55^{\circ} \mathrm{C}$ for adjustment of amounts of DM to be offered daily, and stored for later analyses as monthly composition. The DMI of individual cows were calculated based on the DM of feed measurement at $105^{\circ} \mathrm{C}$.

\section{Measurements of Milk and Milk Components}

Cows were milked twice daily at approximately 0830 and $2030 \mathrm{~h}$ and individual yield of milk was recorded by the Afikim milking system (AfiFlo milk meters, S.A.E. Afikim, Israel). Once weekly, milk was sampled in 2 consecutive milkings and shipped to Southeast DHIA laboratory in Belleview, Florida, for analyses of concentrations of fat, true protein, lactose, and somatic cells. Milk components were adjusted for the yield of milk in each milking to calculate the daily yields and concentrations of fat, true protein, and lactose, and the content of somatic cells. The $3.5 \%$ FCM yield was calculated as $[(0.4324 \times$ milk yield $)+(16.218 \times$ milk fat yield)] (NRC, 2001). The ECM yield was calculated as $[(0.3246 \times$ milk yield $)+(12.86 \times$ fat yield $)+(7.04$ $\times$ protein yield)] (NRC, 2001). Daily values were averaged into weekly means for statistical analyses.

\section{Body Weight, Body Condition, and Calculation of Energy Balance}

Cows were weighed on a walk-though scale (AfiWeigh, S.A.E. Afikim) located on the exit lane of the milking parlor twice daily immediately after each milking. Body condition was scored once weekly using a 1 to 5 scale (Ferguson et al., 1994) with increments of 0.25
Table 1. Ingredient composition and nutrient content of treatment diets

\begin{tabular}{lcc}
\hline & \multicolumn{2}{c}{ Diet $^{1}$} \\
\cline { 2 - 3 } Item & Low starch & High starch \\
\hline Ingredient, \% of diet DM & 39.1 & 32.7 \\
Corn silage & 10.9 & 9.1 \\
Triticale silage & 11.7 & 21.7 \\
Corn, finely ground & 12.0 & 11.6 \\
Soybean hulls & 4.4 & 3.6 \\
Citrus pulp, dry & 4.4 & 3.6 \\
Whole cottonseed & 8.7 & 9.7 \\
Soybean meal, solvent extracted & 4.4 & 3.6 \\
Soybean meal, cooker-processed & \\
Mineral-vitamin-protein mix ${ }^{3}$ & 4.4 & 4.4 \\
Nutrient content, ${ }^{4}$ DM basis & & \\
(mean \pm SD) & 1.54 & 1.56 \\
NE ${ }_{\mathrm{L}}{ }^{5}$ Mcal/kg & kg & $93.5 \pm 0.3$ \\
OM, \% & $14.6 \pm 0.6$ & $14.6 \pm 0.5$ \\
CP, \% & $36.6 \pm 1.3$ & $40.3 \pm 1.1$ \\
NFC, \% & $23.2 \pm 1.7$ & $29.0 \pm 1.2$ \\
Starch, \% & $38.1 \pm 1.0$ & $32.9 \pm 0.8$ \\
NDF, \% & $21.0 \pm 1.1$ & $17.0 \pm 0.9$ \\
Forage NDF, \% & $21.7 \pm 0.7$ & $19.5 \pm 0.6$ \\
ADF, \% & $3.9 \pm 0.1$ & $3.7 \pm 0.1$ \\
Ether extract, \% &
\end{tabular}

${ }^{1}$ Within each of the 2 diets, cows were supplemented with either 15 $\mathrm{g} / \mathrm{d}$ of corn meal or $15 \mathrm{~g} / \mathrm{d}$ of yeast culture (Saccharomyces cerevisiae, Rumen Yeast, ICC, São Paulo, Brazil).

${ }^{2}$ AminoPlus, Ag Processing Inc., Omaha, NE.

${ }^{3}$ The vitamin-mineral-protein premix added to the concentrate and grain supplement contained (DM basis) 30.0\% LysAAmet blood meal (Perdue Agribusiness, Salisbury, MD), 28.5\% sodium sesquicarbonate, $13.0 \%$ potassium carbonate, $9.0 \%$ calcium carbonate, $7.0 \%$ dicalcium phosphate, $7.0 \%$ magnesium oxide, $3.5 \%$ sodium chloride, $1.2 \%$ Availa-4 (Zinpro Co., Eden Prairie, MN), 0.33\% Sel-Plex 2000 (Alltech Biotechnology, Nicholasville, KY), $0.002 \%$ calcium iodate, $0.08 \%$ premix containing vitamins $\mathrm{A}, \mathrm{D}$, and $\mathrm{E}$, and $0.22 \%$ Rumensin 90 (Elanco Animal Health, Greenfield, IN). Each kilogram contains $26.4 \% \mathrm{CP}$, $5.2 \% \mathrm{Ca}, 1.4 \% \mathrm{P}, 3.9 \% \mathrm{Mg}, 9.5 \% \mathrm{Na}, 2.6 \% \mathrm{Cl}, 652 \mathrm{mg}$ of $\mathrm{Zn}, 226 \mathrm{mg}$ of $\mathrm{Cu}, 412 \mathrm{mg}$ of $\mathrm{Mn}, 6.6 \mathrm{mg}$ of Se, $25 \mathrm{mg}$ of Co, $13 \mathrm{mg}$ of I, 112,000 IU of vitamin A, 34,000 IU of vitamin D, 1,100 IU of vitamin E, and $476 \mathrm{mg}$ of monensin.

${ }^{4}$ Means \pm SD of 4 monthly composite samples of forages and concentrates analyzed.

${ }^{5}$ Calculated based on the chemical composition of the dietary ingredients and adjusted for $25 \mathrm{~kg}$ of DMI (NRC, 2001).

units by the same trained evaluator. Energy balance was calculated using daily caloric intake based on the DMI of each cow and the caloric density of diets minus the summation of daily calories required for maintenance $\left(0.08 \times \mathrm{BW}^{0.75}\right)$ and calories secreted as milk according to yields of fat, protein, and lactose milk yield $\times[(0.0929 \times$ fat $\%)+(0.0563 \times$ protein $\%)+$ $(0.0395 \times$ lactose \%) $]\}$ according to NRC (2001). Daily values were averaged into weekly means for statistical analyses.

\section{Blood Sampling and Analyses}

Approximately $8 \mathrm{~mL}$ of blood was sampled once in the last day of the pretreatment period, and then twice 
weekly in the first 5 wk of feeding the experimental treatments. Blood was sampled approximately $2 \mathrm{~h}$ after the morning feeding by puncture of the coccygeal blood vessels into evacuated tubes containing $\mathrm{K}_{2}$ EDTA (Vacutainer, Becton Dickinson, Franklin Lakes, NJ). Blood tubes were placed in ice and transported to the laboratory within $1 \mathrm{~h}$ of sampling and were centrifuged at $3,000 \times g$ for $15 \mathrm{~min}$ at $4^{\circ} \mathrm{C}$ for plasma separation. Plasma was frozen at $-25^{\circ} \mathrm{C}$ for later analyses. Concentrations of glucose (Bran and Luebbe Industrial Method 339-19; Gochman and Schmitz, 1972) and urea N (Bran and Luebbe Industrial Method 339-01; Marsh et al., 1965) were analyzed using an autoanalyzer (Technicon Instruments Corp., Tarrytown, NY). Concentrations of nonesterified fatty acids were analyzed according with Johnson and Peters (1993) using a commercial kit (NEFA-C kit, Wako Fine Chemical Industries Inc., Dallas, TX) and those of haptoglobin were analyzed according to Makimura and Suzuki (1982).

\section{Sampling and Analyses of Feed Ingredients}

Twice weekly, diets and ingredients were sampled, dried at $55^{\circ} \mathrm{C}$, and stored for later analyses as monthly composites. Dried monthly composite samples of corn silage, triticale silage, and concentrates were ground to pass a 1-mm screen of a Wiley mill (Thomas Scientific, Swedesboro, NJ). Samples were then analyzed for $\mathrm{DM}\left(105^{\circ} \mathrm{C}\right.$ for $\left.12 \mathrm{~h}\right), \mathrm{OM}\left(512^{\circ} \mathrm{C}\right.$ for $\left.8 \mathrm{~h}\right)$, sequential analysis of NDF using a heat-stable $\alpha$-amylase and ADF (Van Soest et al., 1991) with the Ankom Fiber Analyzer system (Ankom Technology, Macedon, NY), $\mathrm{N}$ using an automated quantitative combustion digestion method (Elementar Analysensysteme, Elementar Americas Inc., Mt. Laurel, NJ), and starch using an enzymatic digestion method according to Karkalas (1985). The energy density of the diet was estimated using analyzed feed values and calculated according to NRC (2001) adjusted for $25 \mathrm{~kg}$ of DMI. The particle size of finely ground corn was estimated by dry-sieving using a 10-sieve shaker with apertures $(\mu \mathrm{m})$ of 3,360 , 2,380, 1,680, 841, 594, 420, 297, 212, 150, 73, and pan according to the method described by Baker and Herrman (2002).

\section{Feeding Behavior}

Feeding behavior of all cows was evaluated during 2 consecutive days on wk 5 of the experiment when cows had been fed the treatment diets for 34 and $35 \mathrm{~d}$. In those days, the total amount of feed allotted daily was offered once, immediately after the morning milking. Cows were observed every 5 min starting immediately after the morning milking for the next $12 \mathrm{~h}$ as described in Maltz et al. (2013). The location and activity of each cow was recorded as ruminating standing, ruminating lying in the stall, standing only, lying only, eating, and drinking. Each observation was assumed to last $5 \mathrm{~min}$, which was the interval between observations. Chewing was considered as the summation of rumination and eating. The number of eating, lying, and chewing bouts, duration of each meal, total time eating, total time ruminating only, and total time chewing were calculated. Concurrently, a sample of feed of approximately $300 \mathrm{~g}$ was collected immediately after morning feeding and again at $3,6,9,12$, and $24 \mathrm{~h}$ later and screened to determine particle size distribution of the diet of each cow using the 4-sieve ( $>19.0 \mathrm{~mm}, 8.0$ to $19.0 \mathrm{~mm}, 1.18$ to $8.0 \mathrm{~mm}$, and $<1.18 \mathrm{~mm}$ ) Penn State Particle Separator. Feed left in the bunk of each cow was weighed at 12 and $24 \mathrm{~h}$ after feeding and the DMI at both times were calculated. The DM contents of the diets offered and refused at $24 \mathrm{~h}$ of each cow were analyzed.

\section{Subacute Ruminal Acidosis Challenge}

Cows were subjected to a single subacute ruminal acidosis challenge on d 92 of the experiment, corresponding to the first day of wk 14 in the experiment. After the morning milking and before feeding, cows received $3.0 \mathrm{~kg}$ of DM of finely ground corn grain. Feed was withheld for $2 \mathrm{~h}$ to ensure that all cows consumed all the grain, after which cows were fed as described before. The treatment diets continued for 3 more days. Milk samples were collected in 4 milkings preceding the challenge and then at each of the next 6 milkings subsequent to the challenge. Milk samples were shipped to the local DHIA laboratory and analyzed for fat, protein, lactose, and SCC. Data were analyzed as observed values as well as the relative change from the value mean value measured pre-challenge. For milk components, the value pre-challenge was the average of the 4 milkings preceding the challenge.

Blood was sampled immediately before the challenge and again at 4,8 , and $12 \mathrm{~h}$ later by puncture of the coccygeal vessels into evacuated tubes containing $\mathrm{K}_{2}$ EDTA. Blood tubes were immediately placed in ice, processed for plasma separation, and plasma analyzed for concentrations of glucose, nonesterified fatty acids, urea $\mathrm{N}$, and haptoglobin as described previously.

Rumen fluid was collected between 5 and $6 \mathrm{~h}$ after the corn grain challenge through rumenocentesis performed by puncture of the left ventral region of the abdomen using an 18-gauge, 14-cm disposable sterile needle attached to a $12-\mathrm{mL}$ syringe. Samples from 5 of the 56 cows were not used because of either contamination with blood or because the sample likely originated from the abomasum as the $\mathrm{pH}$ was less than 
3.0. Approximately $10 \mathrm{~mL}$ of rumen fluid was collected, the $\mathrm{pH}$ measured immediately, and then acidified with $50 \%$ sulfuric acid solution to a $\mathrm{pH} 2$ with subsequent centrifugation at $5,400 \times g$ for $20 \mathrm{~min}$ at $4^{\circ} \mathrm{C}$. The supernatant was collected and frozen at $-20^{\circ} \mathrm{C}$ until further analysis of short-chain fatty acids (SCFA), lactate, and $\mathrm{NH}_{3}-\mathrm{N}$ concentrations.

Samples of frozen rumen fluid were thawed, centrifuged at $4^{\circ} \mathrm{C}$ and $21,500 \times g$ for $20 \mathrm{~min}$, and the supernatant was analyzed in triplicates for concentrations of organic acids using the method of Canale et al. (1984) by HPLC (Hitachi L2400, Tokyo, Japan) coupled to a UV detector set at $210 \mathrm{~nm}$ and an Aminex HPX-87H column (Bio-Rad Laboratories, Hercules, CA) with $0.015 M$ sulfuric acid mobile phase and a flow rate of $0.7 \mathrm{~mL} / \mathrm{min}$ at $45^{\circ} \mathrm{C}$ and crotonic acid as internal standard. The supernatant was also analyzed for concentration of $\mathrm{NH}_{3}-\mathrm{N}$ according to the procedure of Noel and Hambleton (1976) following colorimetric N quantification using an Autoanalyzer Technicon (Technicon, Tarrytown, NJ).

\section{Statistical Analyses}

Continuous data were evaluated for distribution of the residuals and homogeneity of variance after fitting the statistical models. Data with deviations from normality were subjected to power transformation before final analyses according to the Box-Cox method (Box and Cox, 1964) using the TRANSREG procedure of SAS (SAS/STAT ver. 9.4, SAS Institute Inc., Cary, NC). The LSM and SEM of transformed data were back transformed for presentation according to Jørgensen and Pedersen (1998). Data were analyzed by the MIXED procedure of SAS (SAS/STAT ver. 9.4). Data were analyzed for the pre-challenge period, corresponding to the first $13 \mathrm{wk}$ in the experiment, and the postchallenge period separately.

Statistical models included the fixed effects of level of starch (LS vs. HS), supplementation with yeast culture (control vs. YC), the interaction between starch and yeast culture, and the random effect of block. For responses analyzed with repeated measures within cow, then the models also included the fixed effects of time (hour, day, or week), interactions between level of starch and time, yeast culture and time, the interaction between level of starch and yeast culture and time, and the random effect of cow nested within level of starch and yeast culture. The covariance structure that resulted in best fit based on the smallest corrected Akaike's information criterion was chosen. The Kenward-Roger method was used to calculate the approximate denominator degrees of freedom for the $F$ tests in the mixed models. Measurements taken during the pre-treatment period were used as covariates in the statistical models. For diet particle size selection, the particle size at $\mathrm{h} 0$ was used as covariate. When an interaction between level of starch and yeast culture was detected $(P<$ $0.10)$, then comparisons among individual treatments were adjusted by the method of Tukey. Statistical significance was considered at a $P \leq 0.05$, and tendency was considered at a $P \leq 0.10$.

\section{RESULTS}

All 56 cows completed the 98-d experiment and contributed data for statistical analyses.

\section{Production Performance}

Altering the level of dietary starch or supplementing $\mathrm{YC}$ to the diets did not influence DMI of cows, which averaged $25.4 \mathrm{~kg} / \mathrm{d}$ (Table 2$)$. Treatments tended $(P=$ $0.09)$ to affect milk yield because cows fed HS tended to produce $1.5 \mathrm{~kg}$ more milk than cows fed LS (LS $=38.7$ vs. $40.2 \mathrm{~kg} / \mathrm{d}$ ) and those supplemented with YC also tended to produce $1.5 \mathrm{~kg} / \mathrm{d}$ more milk than controls (control $=38.7$ vs. $Y C=40.2 \mathrm{~kg} / \mathrm{d}$ ). After adjusting for milk components, the $3.5 \% \mathrm{FCM}$ and ECM increased $(P<0.05)$, respectively, 2.2 (control $=40.3$ vs. $\mathrm{YC}=$ $42.5 \mathrm{~kg} / \mathrm{d}$ ) and $2.0 \mathrm{~kg} / \mathrm{d}$ (control $=39.2$ vs. $\mathrm{YC}=41.2$ $\mathrm{kg} / \mathrm{d}$ ) in cows supplemented with YC; however, altering the level of dietary starch from 23 to $29 \%$ did not affect yields of $3.5 \%$ FCM or ECM. Treatments did not affect efficiency of feed conversion into 3.5\% FCM or ECM, which averaged 1.64 and 1.60, respectively.

Feeding HS tended $(P=0.09)$ to decrease milk fat percentage compared with LS $(\mathrm{LS}=3.87$ vs. HS $=$ $3.75 \%$ ), but no difference was observed with supplementing YC. The yield of milk fat increased $(P=0.05)$ by supplementing $\mathrm{YC}$ (control $=1.45$ vs. $\mathrm{YC}=1.55$ $\mathrm{kg} / \mathrm{d}$ ), but it was not influenced by level of dietary starch. The percentage and yield of milk true protein increased $(P=0.01)$ in cows fed the HS $(3.01 \%$ and $1.20 \mathrm{~kg} / \mathrm{d})$ compared with the LS $(2.87 \%$ and 1.11 $\mathrm{kg} / \mathrm{d})$, and supplementing $\mathrm{YC}$ also increased $(P=0.04)$ milk true protein yield compared with control (control $=1.12 \mathrm{vs} . \mathrm{YC}=1.18 \mathrm{~kg} / \mathrm{d}$ ). The content of lactose in milk did not differ among treatments, but supplementing cows with $\mathrm{YC}$ tended $(P=0.06)$ to increase lactose yield compared with control (control $=1.90$ vs. $\mathrm{YC}$ $=1.98 \mathrm{~kg} / \mathrm{d}$ ). The changes in milk composition were not sufficient to alter the net energy (NE) content in milk, which averaged $0.71 \mathrm{Mcal} / \mathrm{kg}$, but feeding YC resulted in greater $(P=0.04) \mathrm{NE}$ secretion as milk than feeding control (control $=27.3$ vs. $\mathrm{YC}=28.8$ $\mathrm{Mcal} / \mathrm{d}$ ). Treatments did not alter the NE balance or BW of cows, and they averaged $1.47 \mathrm{Mcal} / \mathrm{d}$ and 607 
$\mathrm{kg}$, respectively. Despite the lack of differences in measures of energy status, small differences in BCS were observed among treatments and cows fed YC tended $(P=0.06)$ to have slightly greater BCS throughout the experiment compared with the control, although the difference was small (control $=2.87$ vs. $\mathrm{YC}=2.96$ ). None of the production responses evaluated were affected by the interaction between level of dietary starch and supplementation with YC.

\section{Plasma Metabolites}

Cows fed HS had greater $(P=0.02)$ concentration of glucose than those fed LS (LS $=62.2$ vs. HS $=63.8$ $\mathrm{mg} / \mathrm{dL}$; Table 3). Concentrations of nonesterified fatty acids in plasma were low $(154 \mu M)$ because cows were in positive NE balance, and they did not differ among treatments. On the other hand, feeding HS decreased $(P=0.02)$ the concentrations of urea $\mathrm{N}$ in plasma compared with feeding the LS diet ( $\mathrm{LS}=10.1$ vs. $\mathrm{HS}=9.4$ $\mathrm{mg} / \mathrm{dL}$ ). Concentration of haptoglobin in plasma was not affected by level of dietary starch, but supplement- ing the diet with $\mathrm{YC}$ tended $(P=0.07)$ to decrease haptoglobin concentration compared with control (control $=5.78$ vs. $\mathrm{YC}=5.13 \mathrm{OD} \times 100)$.

\section{Feeding Behavior}

During the 2-d feeding behavior observation, the DMI of cows for the first $12 \mathrm{~h}$ of feeding or the entire day was affected by an interaction between level of dietary starch and YC (Table 4). In the first 12-h of observation, feeding HS reduced DMI, but that was only observed in control cows. Similarly, in the 24-h period, HS decreased DMI in cows fed control, but not in those supplemented with YC. The time spent eating in the first $12 \mathrm{~h}$ decreased $(P=0.01)$ approximately 18 min (10\%) in cows fed HS compared with those fed LS; however, YC or the interaction between level of dietary starch and YC did not influence eating time. Ruminating time tended $(P=0.08)$ to be affected by an interaction between dietary starch and supplemental YC because feeding YC in LS increased the time spent ruminating, resulting in LS-YC spending 24 min more

Table 2. Effect of concentration of dietary starch and supplementation with yeast culture (YC) on performance of Holstein cows

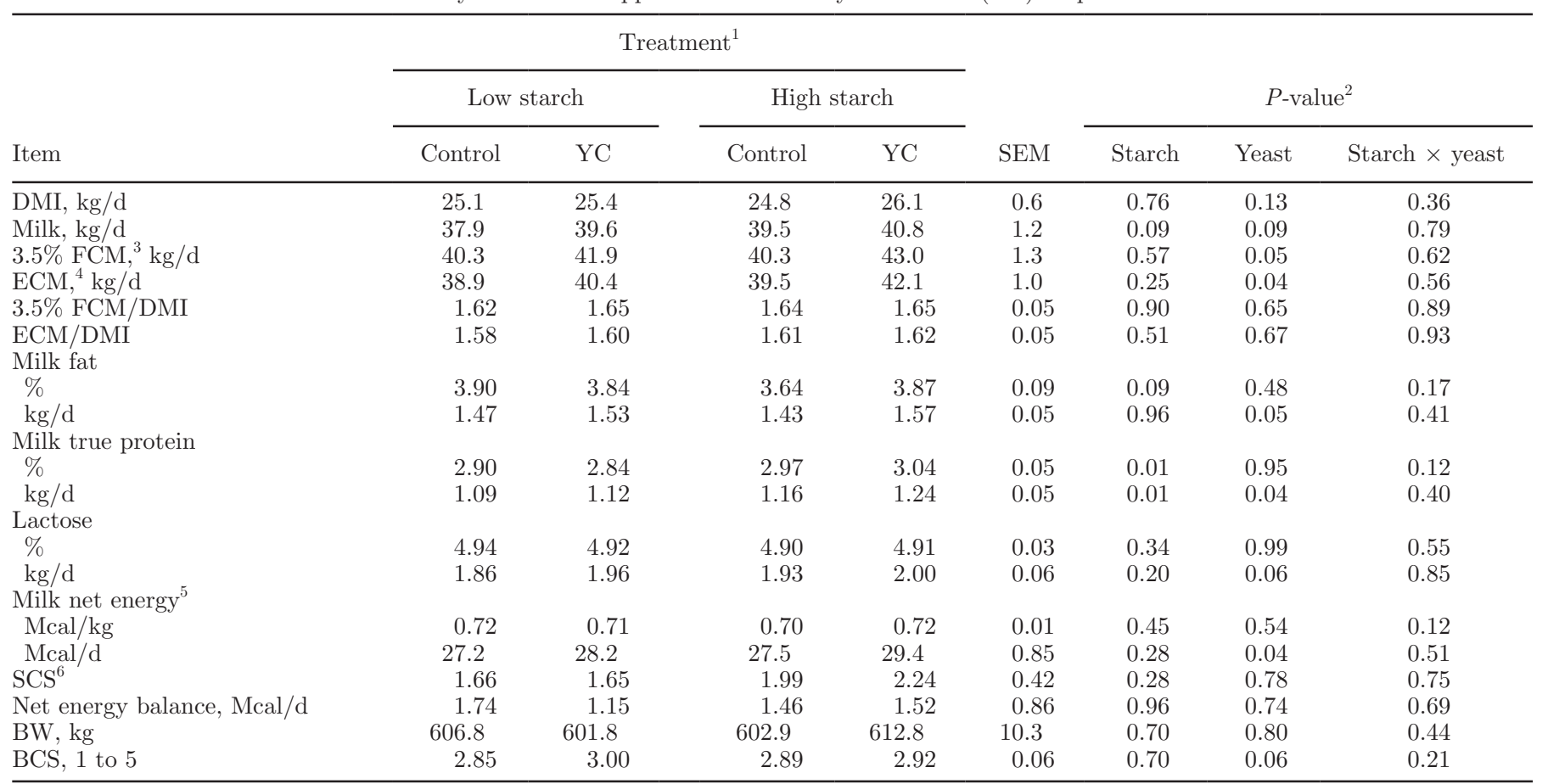

${ }^{1}$ Cows were fed diets containing either 23 (low) or $29 \%$ (high) starch and not supplemented (control) or supplemented with $15 \mathrm{~g} / \mathrm{d}$ of yeast culture.

${ }^{2}$ Starch $=$ effect of level of dietary starch (23 vs. $29 \%$ ); yeast $=$ effect of yeast culture (control vs. YC); starch $\times$ yeast $=$ interaction between starch and yeast.

${ }^{3} 3.5 \% \mathrm{FCM}=(0.4324 \times$ milk kg $)+(16.218 \times$ fat yield $\mathrm{kg})$.

${ }^{4} \mathrm{ECM}=(0.3246 \times$ milk $\mathrm{kg})+(12.86 \times$ fat yield $\mathrm{kg})+(7.04 \times$ protein yield $\mathrm{kg})$.

${ }^{5}$ Milk net energy content $=(0.0929 \times \%$ milk fat $)+(0.0563 \times \%$ milk true protein $)+(0.0395 \times \%$ lactose $)$.

${ }^{6} \mathrm{SCS}=\log _{10}(\mathrm{SCC} / 12.5) / \log _{10} 2$. 
Table 3. Effect of concentration of dietary starch and supplementation with yeast culture (YC) on plasma metabolites of Holstein cows in the first $5 \mathrm{wk}$ in the experiment

\begin{tabular}{|c|c|c|c|c|c|c|c|c|}
\hline Item & \multicolumn{4}{|c|}{ Treatment $^{1}$} & SEM & & & \\
\hline Glucose, mg/dL & 61.6 & 62.7 & 64.3 & 63.2 & 0.7 & 0.02 & 0.98 & 0.13 \\
\hline Nonesterified fatty acids, $\mu M$ & 156.1 & 158.6 & 139.8 & 160.4 & 19.7 & 0.70 & 0.53 & 0.62 \\
\hline Urea $\mathrm{N}, \mathrm{mg} / \mathrm{dL}$ & 10.0 & 10.1 & 9.7 & 9.0 & 0.3 & 0.02 & 0.28 & 0.14 \\
\hline
\end{tabular}

${ }^{1}$ Cows were fed diets containing either 23 (low) or $29 \%$ (high) starch and not supplemented (control) or supplemented with $15 \mathrm{~g} / \mathrm{d}$ yeast culture. ${ }^{2}$ Starch $=$ effect of level of dietary starch (23 vs. $29 \%$ ); yeast $=$ effect of yeast culture (control vs. YC); starch $\times$ yeast $=$ interaction between starch and yeast.

ruminating than those fed the other 3 treatments. The increase in ruminating time observed in cows fed LS-YC was detected when they were either lying or standing. Cows fed HS spent fewer $(P=0.01)$ minutes chewing than cows fed LS diet, but no effect was observed by supplementing YC. The times spent drinking or lying did not differ with treatments.

The number of eating bouts increased $(P<0.01)$ in cows fed HS compared with cows fed LS (LS $=5.5$ vs. HS $=6.9$ bouts $/ 12 \mathrm{~h})$, and tended $(P=0.09)$ to increase with supplemental $\mathrm{YC}$ (control $=5.9$ vs. YC $=6.4$ bouts $/ 12 \mathrm{~h}$; Table 4 ). Similarly, the number of chewing bouts increased $(P<0.01)$ by feeding HS compared with LS (LS $=11.0$ vs. HS $=12.2$ bouts $/ 12$ h) and tended $(P=0.06)$ to increase with feeding $\mathrm{YC}$ (control $=11.2$ vs. $\mathrm{YC}=12.0$ bouts $/ 12 \mathrm{~h}$ ). Treatments did not affect the number of rumination bouts, which averaged 5.4/12 h. Meal duration and meal size were both influenced by the interaction between level of starch and supplemental YC. Cows fed LS had longer $(P<0.01)$ meals than those fed HS, but this effect was greater in those fed control compared with YC. Similar, meal size was greater $(P<0.01)$ for cows fed LS than HS, but this effect was exacerbated in LS-control than

Table 4. Effect of concentration of dietary starch and supplementation with yeast culture (YC) on feeding behavior of Holstein cows

\begin{tabular}{|c|c|c|c|c|c|c|c|c|}
\hline \multirow[b]{3}{*}{ Item } & \multicolumn{4}{|c|}{ Treatment $^{1}$} & \multirow[b]{3}{*}{ SEM } & \multirow{2}{*}{\multicolumn{3}{|c|}{$P$-value ${ }^{2}$}} \\
\hline & \multicolumn{2}{|c|}{ Low starch } & \multicolumn{2}{|c|}{ High starch } & & & & \\
\hline & Control & $\mathrm{YC}$ & Control & $\mathrm{YC}$ & & Starch & Yeast & Starch $\times$ yeast \\
\hline \multicolumn{9}{|l|}{ DMI, kg } \\
\hline $12 \mathrm{~h}$ & $24.8^{\mathrm{a}}$ & $23.4^{\mathrm{ab}}$ & $22.0^{\mathrm{b}}$ & $24.2^{\mathrm{a}}$ & 0.6 & 0.06 & 0.51 & $<0.01$ \\
\hline $24 \mathrm{~h}$ & $28.5^{\mathrm{a}}$ & $27.8^{\mathrm{ab}}$ & $26.3^{\mathrm{b}}$ & $28.5^{\mathrm{a}}$ & 0.7 & 0.20 & 0.22 & 0.02 \\
\hline Eating, $\min / 12 \mathrm{~h}$ & 183.4 & 170.3 & 156.9 & 161.4 & 8.3 & 0.01 & 0.54 & 0.21 \\
\hline \multicolumn{9}{|l|}{ Ruminating, $\min / 12 \mathrm{~h}$} \\
\hline Standing & 31.7 & 44.9 & 33.1 & 39.0 & 5.8 & 0.70 & 0.10 & 0.52 \\
\hline Lying & 155.5 & 162.0 & 155.3 & 147.3 & 11.2 & 0.43 & 0.94 & 0.44 \\
\hline Total & $187.6^{\mathrm{AB}}$ & $211.3^{\mathrm{A}}$ & $188.9^{\mathrm{AB}}$ & $186.7^{\mathrm{B}}$ & 8.8 & 0.10 & 0.15 & 0.08 \\
\hline Total chewing, $\min / 12 \mathrm{~h}$ & 371.0 & 381.6 & 345.8 & 348.2 & 11.9 & 0.01 & 0.55 & 0.71 \\
\hline Drinking, $\min / 12 \mathrm{~h}$ & 23.5 & 23.6 & 21.7 & 22.8 & 2.3 & 0.53 & 0.78 & 0.82 \\
\hline Lying, $\min / 12 \mathrm{~h}$ & 318.5 & 322.6 & 340.4 & 314.2 & 17.0 & 0.66 & 0.47 & 0.32 \\
\hline \multicolumn{9}{|l|}{ Bouts, no./12 h } \\
\hline Eating & 5.2 & 5.7 & 6.6 & 7.2 & 0.4 & $<0.01$ & 0.09 & 0.82 \\
\hline Rumination & 5.4 & 5.7 & 5.2 & 5.4 & 0.3 & 0.40 & 0.33 & 0.89 \\
\hline Chewing & 10.6 & 11.4 & 11.8 & 12.6 & 0.5 & $<0.01$ & 0.06 & 0.93 \\
\hline Meal duration, min/meal & $36.5^{\mathrm{a}}$ & $30.8^{\mathrm{b}}$ & $24.7^{\mathrm{c}}$ & $24.3^{\mathrm{c}}$ & 1.6 & $<0.01$ & 0.06 & 0.10 \\
\hline Meal size, $\mathrm{kg} / \mathrm{meal}$ & $4.95^{\mathrm{a}}$ & $4.22^{\mathrm{b}}$ & $3.53^{\mathrm{c}}$ & $3.61^{\mathrm{c}}$ & 0.23 & $<0.01$ & 0.12 & 0.05 \\
\hline Intermeal interval, min & 108.6 & 98.2 & 85.5 & 79.1 & 5.2 & $<0.01$ & 0.07 & 0.66 \\
\hline Eating rate, $\mathrm{g} / \mathrm{min}$ & 138.0 & 139.5 & 146.4 & 153.1 & 7.1 & 0.09 & 0.53 & 0.69 \\
\hline
\end{tabular}

${ }^{\mathrm{a}-\mathrm{c}}$ Different superscripts in the same row differ $(P \leq 0.05)$ after adjustment by the method of Tukey.

${ }^{\mathrm{A}, \mathrm{B}}$ Different superscripts in the same row differ $(P=0.07)$ after adjustment by the method of Tukey.

${ }^{1}$ Cows were fed diets containing either 23 (low) or $29 \%$ (high) starch and not supplemented (control) or supplemented with 15 g/d yeast culture.

${ }^{2}$ Starch $=$ effect of level of dietary starch (23 vs. $29 \%$ ); yeast $=$ effect of yeast culture $($ control vs. YC); starch $\times$ yeast $=$ interaction between starch and yeast. 
LS-YC. Intermeal interval was longer $(P<0.01)$ in cows fed LS than HS (LS $=103.4$ vs. HS $=82.3 \mathrm{~min}$ ), and tended $(P=0.07)$ to be longer for control than YC cows $(97.0$ vs. $88.7 \mathrm{~min})$. Eating rate tended $(P=0.09)$ to be greater for cows fed HS than LS (138 vs. $150 \mathrm{~g} /$ min), but it was not influenced by supplemental YC.

Particle size of the TMR, as expected, was affected by level of dietary starch because the LS diet contained more forage and, therefore, had a larger proportion of longer particles (Figure 1). At h 0 , the proportion of particles longer than $19 \mathrm{~mm}$ was greater $(P<0.01)$ for LS than HS ( $\mathrm{LS}=11.6$ vs. HS $=9.7 \%)$. Also, at h 0 , a larger $(P<0.01)$ proportion of particles between 8 and $19 \mathrm{~mm}$ in length was detected in cows fed LS than HS ( $\mathrm{LS}=37.5$ vs. $\mathrm{HS}=34.2 \%)$. Consequently, cows fed LS had TMR with lesser $(P<0.01)$ proportions of particles between 1.18 and $8 \mathrm{~mm}(\mathrm{LS}=30.9$ vs. $\mathrm{HS}=$ $32.1 \%)$ and smaller than $1.18 \mathrm{~mm}(\mathrm{LS}=20.0 \mathrm{vs}$. HS $=$ $24.0 \%$ ). No differences were observed between diets of cows fed control or YC.

Cows selected against particles longer than $19 \mathrm{~mm}$ and favored ingestion of smaller particles over the course of $24 \mathrm{~h}$, particularly those fed LS compared with HS (Figure 1). Nevertheless, interactions between level of starch and YC $(P=0.02)$, and among level of starch, $\mathrm{YC}$, and hour $(P=0.04)$ were detected for particles $>19 \mathrm{~mm}$. The proportions of particles $>19$ $\mathrm{mm}$ increased over time for all treatments, but to a lesser extent in HS-control. At $24 \mathrm{~h}$ after feeding, the proportions of particles $>19 \mathrm{~mm}$ did not differ between LS-control and LS-YC (LS-control $=17.8$ vs. LS-YC $=$ $16.5 \%$ ), but cows fed HS supplemented with YC sorted against longer particles (HS-control 10.2 vs. HS-YC = $14.0 \%$ ). The proportion of particles with length between 8 and $19 \mathrm{~mm}$ was affected by level of starch $(P<0.01)$ and tended $(P=0.08)$ to be affected by supplementation with YC. Cows fed LS had rations with larger proportion of particles 8 to $19 \mathrm{~mm}$ than cows fed HS throughout the feeding period $(\mathrm{LS}=38.9$ vs. HS $=$ $33.9 \%$ ). Feeding YC tended to favor a larger proportion of particles between 8 to $19 \mathrm{~mm}$ than control (control $=35.7$ vs. $\mathrm{YC}=36.4 \%$ ). For small particles, between 1.18 and $8 \mathrm{~mm}$ and those $<1.18 \mathrm{~mm}$, interactions $(P$ $<0.01$ ) between level of starch, supplemental YC, and hour were detected. Cows fed HS-control selected against particles between 1.18 and 8, which resulted in increased proportion of those particles from 34.0 to $36.2 \%$ from 3 to $24 \mathrm{~h}$, whereas in all other treatments, the proportion of the same particles decreased 1 to 2 percentage units over the $24 \mathrm{~h}$. The proportion of particles $<1.18$ decreased $(P<0.01)$ over the $24 \mathrm{~h}$, but within LS, the decline was more accentuated in control than $\mathrm{YC}$, whereas for $\mathrm{HS}$ diet, the decline was more accentuated for cows fed YC than control.

\section{Challenge with Corn Grain}

The geometric mean particle of the finely ground corn averaged $541.7 \pm 2.7 \mu \mathrm{m}$ with $51.3 \pm 6.3 \%$ of the particles retained in the sieve $\geq 841 \mu \mathrm{m}$. Corn contained $73.8 \pm 1.2 \%$ starch, which resulted in an additional $2.2 \mathrm{~kg}$ of starch fed to cows. Cows were challenged with corn grain in an attempt to induce changes in rumen fermentation. The $\mathrm{pH}$ of the rumen fluid was affected by an interaction $(P=0.03)$ between level of dietary starch and supplementation with YC (Table 5). Increasing the level of dietary starch from LS to HS reduced rumen $\mathrm{pH}$, but this reduction was not observed when cows were supplemented with YC. The proportion of cows with rumen $\mathrm{pH}$ less than 5.80 markedly increased with feeding the HS diet (LS $=8.4$ vs. $\mathrm{HS}=44.6 \%$ ). No interaction between level of dietary starch and supplementation with YC was observed for the proportion of cows with rumen $\mathrm{pH}$ less than 5.80, although supplementing YC to cows fed HS numerically reduced that proportion. The lesser rumen fluid $\mathrm{pH}$ in cows fed the HS compared with cows fed the LS diet was likely caused by the increased $(P<0.01)$ concentrations of lactate and total SCFA in those cows; however, for lactate, an interaction $(P=0.04)$ between dietary starch and $\mathrm{YC}$ was observed because lactate increased with HS, but only when cows were fed control, but not YC. The concentration of total SCFA increased $(P<0.01)$ in cows fed HS because they had greater $(P$ $<0.02)$ concentrations of acetate $(70.2$ vs. $85.4 \mathrm{mM})$ and propionate $(17.6$ vs. $25.0 \mathrm{mM})$, and tended $(P=$ $0.09)$ to have greater concentration of butyrate than cows fed LS (13.0 vs. $16.8 \mathrm{mM}$ ). The changes in SCFA profile resulted in a smaller $(P=0.05)$ ratio of acetate to propionate in cows fed HS than LS (4.22 vs. 3.65). No differences in SCFA concentrations were observed with feeding YC.

After the challenge, concentrations of glucose decreased (effect of hour; $P<0.01$ ), but despite the decline, the mean concentrations remained greater $(P=$ $0.02)$ in cows fed the HS than the LS (63.1 vs. $65.3 \mathrm{mg} /$ dL; Figure 2, panel A). Cows fed the HS tended $(P=$ $0.09)$ to maintain smaller concentrations of nonesterified fatty acids than those fed LS (138.5 vs. $119.0 \mu \mathrm{M}$; Figure 2, panel B). Feeding cows YC had no influence on the concentrations of glucose or nonesterified fatty acids in plasma of cows. Similarly, dietary treatments did not affect the concentrations of urea $\mathrm{N}$ in the $12 \mathrm{~h}$ following the challenge. Concentrations of haptoglobin increased $(P<0.01)$ over time and peaked at $8 \mathrm{~h}$ after the challenge (Figure 2, panel D). Haptoglobin concentrations in plasma were affected by an interaction $(P<$ 0.01 ) between level of dietary starch and supplemental YC. For cows fed control, increasing the level of dietary 

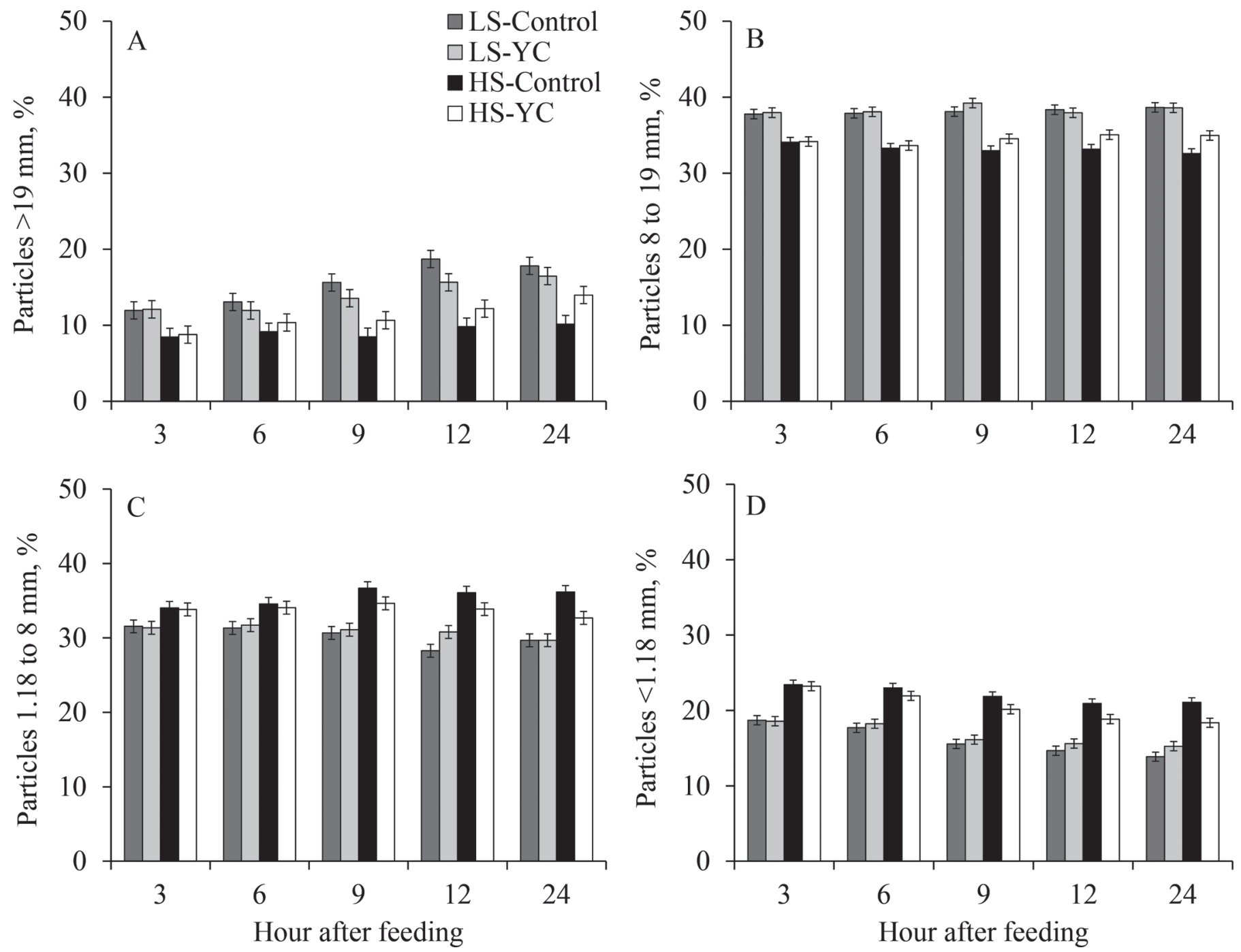

Figure 1. Distribution of particles in the TMR of cows receiving diets containing either 23 (LS) or 29\% (HS) starch and not supplemented (control) or supplemented with $15 \mathrm{~g} / \mathrm{d}$ yeast culture (YC). Particle size distribution was evaluated for individual cows during 2 consecutive days. For particles $>19 \mathrm{~mm}$ (panel A), effects of level of starch $(P<0.01)$, YC $(P=0.75)$, hour $(P<0.01)$, and interactions between level of starch and YC $(P=0.03)$, level of starch and hour $(P<0.01)$, YC and hour $(P=0.56)$, and level of starch and YC and hour $(P=0.04)$. For particles of 8 to $19 \mathrm{~mm}$ (panel B), effects of level of starch $(P<0.01)$, YC $(P=0.08)$, hour $(P=0.64)$, and interactions between level of starch and YC $(P=0.21)$, level of starch and hour $(P=0.40)$, YC and hour $(P=0.35)$, and level of starch and YC and hour $(P=0.22)$. For particles of 1.18 to $8 \mathrm{~mm}$ (panel C), effects of level of starch $(P<0.01)$, YC $(P=0.42)$, hour $(P<0.01)$, and interactions between level of starch and YC $(P=$ $0.08)$, level of starch and hour $(P<0.01)$, YC and hour $(P=0.07)$, and level of starch and $\mathrm{YC}$ and hour $(P<0.01)$. For particles $<1.18 \mathrm{~mm}$ (panel D), effects of level of starch $(P<0.01)$, YC $(P=0.22)$, hour $(P<0.01)$, and interactions between level of starch and YC $(P<0.01)$, level of starch and hour $(P=0.70)$, YC and hour $(P=0.89)$, and level of starch and YC and hour $(P<0.01)$. Error bars represent the SEM.

starch markedly increase plasma haptoglobin concentrations $($ LS-control $=3.8$ vs. HS-control $=6.3 \mathrm{OD} \times$ 100), whereas altering dietary starch when cows were supplemented with YC had no effect on plasma haptoglobin $(\mathrm{LS}-\mathrm{YC}=4.5$ vs. HS-YC $=4.6 \mathrm{OD} \times 100)$. In fact, a tendency $(P=0.07)$ for a 3 -way interaction between dietary starch, $\mathrm{YC}$, and hour after the challenge was observed because of the marked increase in plasma haptoglobin in the first $12 \mathrm{~h}$ after challenge when cows were fed HS-control, a response that was attenuated in all other treatments.
In the $3 \mathrm{~d}$ preceding the challenge, the DMI averaged $27.1 \pm 0.6 \mathrm{~kg} / \mathrm{d}$ and declined $(P=0.04)$ on the day of the challenge in all 4 treatments, reaching a nadir of $25.7 \pm 0.6 \mathrm{~kg} / \mathrm{d}$, and returned to $26.9 \pm 0.6 \mathrm{~kg} / \mathrm{d}$ on d 2 after the challenge. Level of starch or supplementation with YC did not affect the pattern of DMI after the grain challenge.

Concentrations and yields of milk components were evaluated after standardizing them relative to the values measured before the challenge. Challenging cows with corn starch reduced (effect of day, $P<0.05$ ) the 
concentration of fat and NE in milk and the yields of fat, protein, and net energy in milk (Figure 3). The content of true protein in milk remained constant following the challenge. Treatments did not influence any of the measures of milk composition and yield of milk components.

\section{DISCUSSION}

Yeast culture is a common feed additive used in dairy cattle rations to improve yields of milk and milk components (Poppy et al., 2012), or to improve efficiency of feed conversion into FCM (Schingoethe et al., 2004). Supplementing YC to cows in early lactation did not influence DMI, but improved yields of $3.5 \%$ FCM and ECM because of a tendency to increase milk yield and improvements in yields of milk components. The benefits to supplementing $\mathrm{YC}$ were observed in cows fed LS or HS, indicating that improvements in lactation performance were not dependent on level of NDF, forage NDF, or starch in the ration as all 3 components changed from the LS to the HS diet. Nevertheless, the similar NE balance observed for cows in all treatments suggest that increments in yields of FCM and ECM in cows fed YC were mediated in part by the numerical increase in DMI. On the other hand, increasing dietary starch from 23 to $29 \%$ tended to increase milk yield, but did not influence yields of 3.5\% FCM and ECM because of the reduction in milk fat content.

Feeding yeast culture often has been shown to improve lactation performance in dairy cows. In a field experiment with 11 dairy farms, Shaver and Garrett (1997) reported that milk yield increased in 8 of the 11 farms that fed yeast culture. Bruno et al. (2009) reported increases in yields of milk and milk components when cows were supplemented with yeast culture. A comprehensive meta-analysis of a culture of $S$. cerevisiae demonstrated mean $3.5 \%$ FCM and ECM responses of 1.61 and $1.65 \mathrm{~kg} / \mathrm{d}$, respectively, and the increments in lactation performance were accompanied by increases in DMI only when experiments initiated supplementation with yeast culture in early lactation (Poppy et al., 2012). Supplementation with yeast culture starting in early lactation increased DMI $0.62 \mathrm{~kg} / \mathrm{d}$, which explained most of the increments in productive performance (Poppy et al., 2012). Although YC did not affect DMI, the numerical change in intake justifies approximately 2 to $2.2 \mathrm{~kg} / \mathrm{d}$ additional yields of $3.5 \%$ FCM and ECM in cows fed YC. When feeding yeast culture did not influence DMI, it often improved efficiency of feed conversion into ECM (Schingoethe et al., 2004). Poppy et al. (2012) showed that supplementing yeast culture to cows resulted in improvement in yields of 3.5\% FCM and ECM, but in experiments initiating after 70 DIM, intake decreased $0.78 \mathrm{~kg} / \mathrm{d}$, thereby reinforcing the improved feed efficiency when intake is not increased or even reduced by yeast culture. In the current experiment, treatments were initiated early in lactation and production increased with a numerical increase in DMI, resulting in similar feed efficiency as observed for experiments with cows in early lactation reviewed by Poppy et al. (2012).

Several mechanisms have been proposed to justify the benefits of yeast culture on animal performance, and response to $S$. cerevisiae products do not seem to be dependent on the presence of live cells (Nocek et al., 2011; Poppy et al., 2012). Experiments conducted in vivo and in vitro have shown that yeast culture

Table 5. Effect of concentration of dietary starch and supplementation with yeast culture (YC) on rumen fluid parameters of Holstein cows after a challenge with $3 \mathrm{~kg}$ of corn grain DM

\begin{tabular}{|c|c|c|c|c|c|c|c|c|}
\hline Item & \multicolumn{4}{|c|}{ Treatment $^{1}$} & SEM & \multicolumn{3}{|c|}{$P$-value ${ }^{2}$} \\
\hline \multicolumn{9}{|l|}{ Rumen pH } \\
\hline Mean & $6.27^{\mathrm{a}}$ & $6.19^{\mathrm{a}}$ & $5.72^{\mathrm{b}}$ & $6.12^{\mathrm{a}}$ & 0.13 & $<0.01$ & 0.16 & 0.03 \\
\hline$<5.8, \%$ & 9.1 & 7.7 & 53.9 & 35.7 & - & 0.01 & 0.58 & 0.74 \\
\hline \multicolumn{9}{|c|}{ Short-chain fatty acids, $\mathrm{m} M$} \\
\hline Total & 95.8 & 111.1 & 127.9 & 126.1 & 9.8 & 0.01 & 0.44 & 0.33 \\
\hline Acetate & 65.6 & 74.7 & 84.9 & 85.9 & 6.6 & 0.02 & 0.40 & 0.50 \\
\hline Propionate & 17.0 & 18.1 & 24.8 & 25.2 & 2.4 & $<0.01$ & 0.69 & 0.88 \\
\hline Butyrate & 12.6 & 13.4 & 18.3 & 15.2 & 2.3 & 0.09 & 0.61 & 0.37 \\
\hline Acetate:propionate & 4.12 & 4.33 & 3.66 & 3.64 & 0.29 & 0.05 & 0.74 & 0.70 \\
\hline
\end{tabular}

\footnotetext{
${ }^{\mathrm{a}-\mathrm{c}}$ Different superscripts in the same row differ $(P \leq 0.05)$ after adjustment by the method of Tukey.

${ }^{1}$ Cows were fed diets containing either 23 (low) or $29 \%$ (high) starch and not supplemented (control) or supplemented with $15 \mathrm{~g} / \mathrm{d}$ yeast culture. ${ }^{2}$ Starch $=$ effect of level of dietary starch (23 vs. $29 \%$ ); yeast $=$ effect of yeast culture (control vs. YC); starch $\times$ yeast $=$ interaction between starch and yeast.
} 
stimulates growth of rumen cellulolytic bacteria (Harrison et al., 1988; Callaway and Martin, 1997). Results from a companion paper showed that supplementing YC increased rumen NDF digestion when cows were fed the HS diet (Dias et al., 2018). Desnoyers et al. (2009) reviewed the literature on yeast products, including yeast cultures and live yeast products, and found that $S$. cerevisiae supplementation increased OM digestibility and the benefits were greater in diets with more fiber than in diets with more concentrate feeds. In the companion paper, feeding YC improved rumen $\mathrm{NDF}$ digestion, and combining HS-YC resulted in the greatest microbial $\mathrm{N}$ yield (Dias et al., 2018). Williams et al. (1991) showed that yeast culture improved yields of FCM when cows were fed a diet with more concentrates, thereby suggesting that benefits are diet dependent. Contrary to those findings, current results and those of Dias et al. (2018) showed that yields of $3.5 \%$ FCM and ECM increased in cows fed YC despite the starch content of the diet. Therefore, it seems that benefits to supplemental YC are observed in a variety of diet compositions (Shaver and Garrett, 1997).

The yeast culture product fed in YC was top dressed onto the diet and concentrations of the product in the
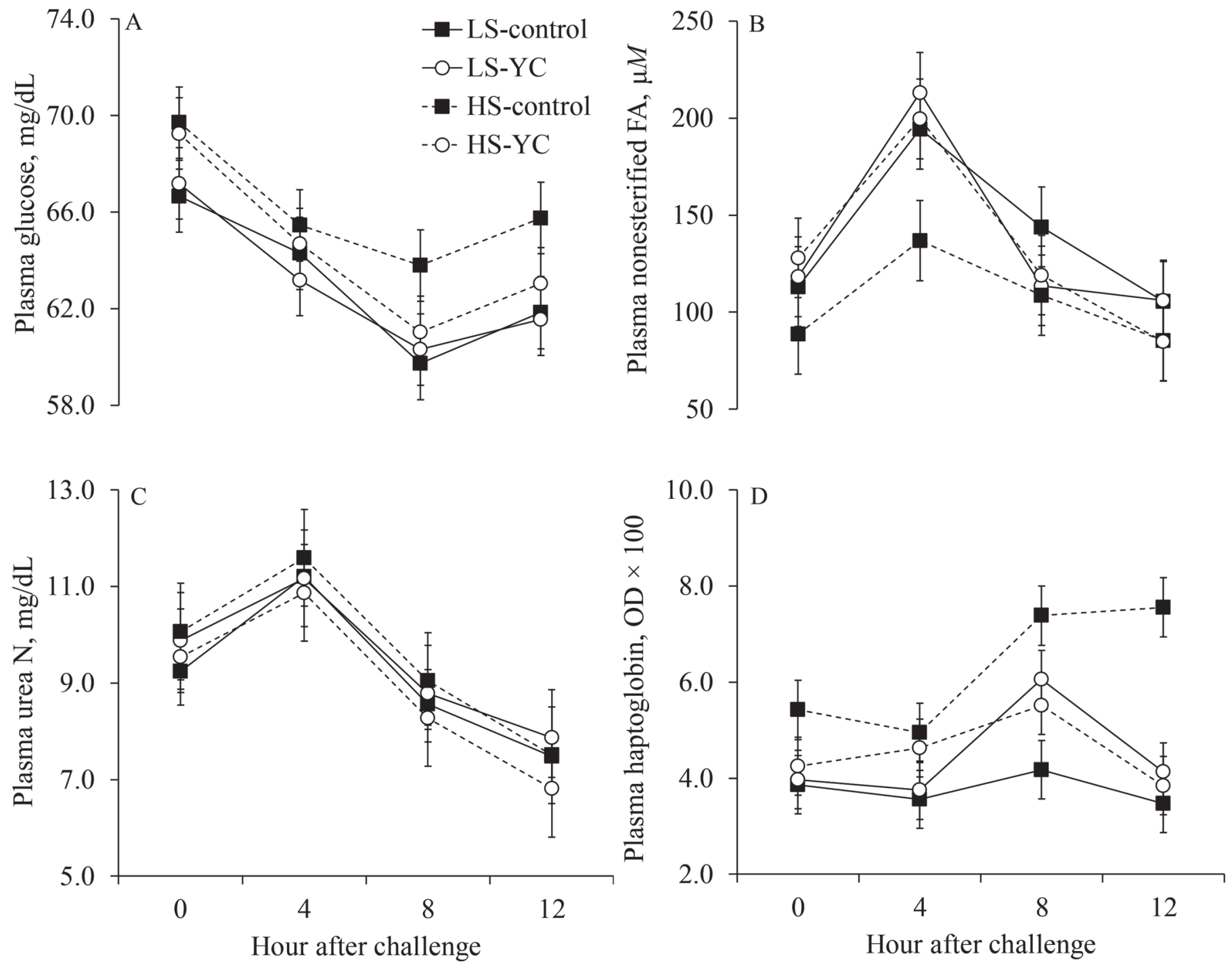

Figure 2. Concentrations of metabolites in plasma after a challenge with $3 \mathrm{~kg}$ of corn DM at h 0 in cows fed diets containing either 23 (LS) or $29 \%$ (HS) starch and not supplemented (control) or supplemented with $15 \mathrm{~g} / \mathrm{d}$ yeast culture (YC). Panel A, plasma glucose concentrations; effects of level of starch $(P=0.02)$, YC $(P=0.35)$, and interaction between level of starch and $\mathrm{YC}(P=0.40)$. Panel B, plasma nonesterified fatty acid (FA) concentrations; effects of level of starch $(P=0.09)$, YC $(P=0.25)$, and interaction between level of starch and YC $(P=0.20)$. Panel C, plasma urea N concentrations; effects of level of starch $(P=0.85)$, YC $(P=0.55)$, and interaction between level of starch and $\mathrm{YC}(P$ $=0.12)$. Panel $\mathrm{D}$, plasma haptoglobin concentrations $(\mathrm{OD}=$ optical density); effects of level of starch $(P<0.01), \mathrm{YC}(P=0.15)$, and interaction between level of starch and YC $(P<0.01)$. Error bars represent SEM $(\mathrm{A}, \mathrm{SEM}=1.5 ; \mathrm{B}, \mathrm{SEM}=20.5 ; \mathrm{C}, \mathrm{SEM}=0.43 ; \mathrm{D}, \mathrm{SEM}=0.61)$. 

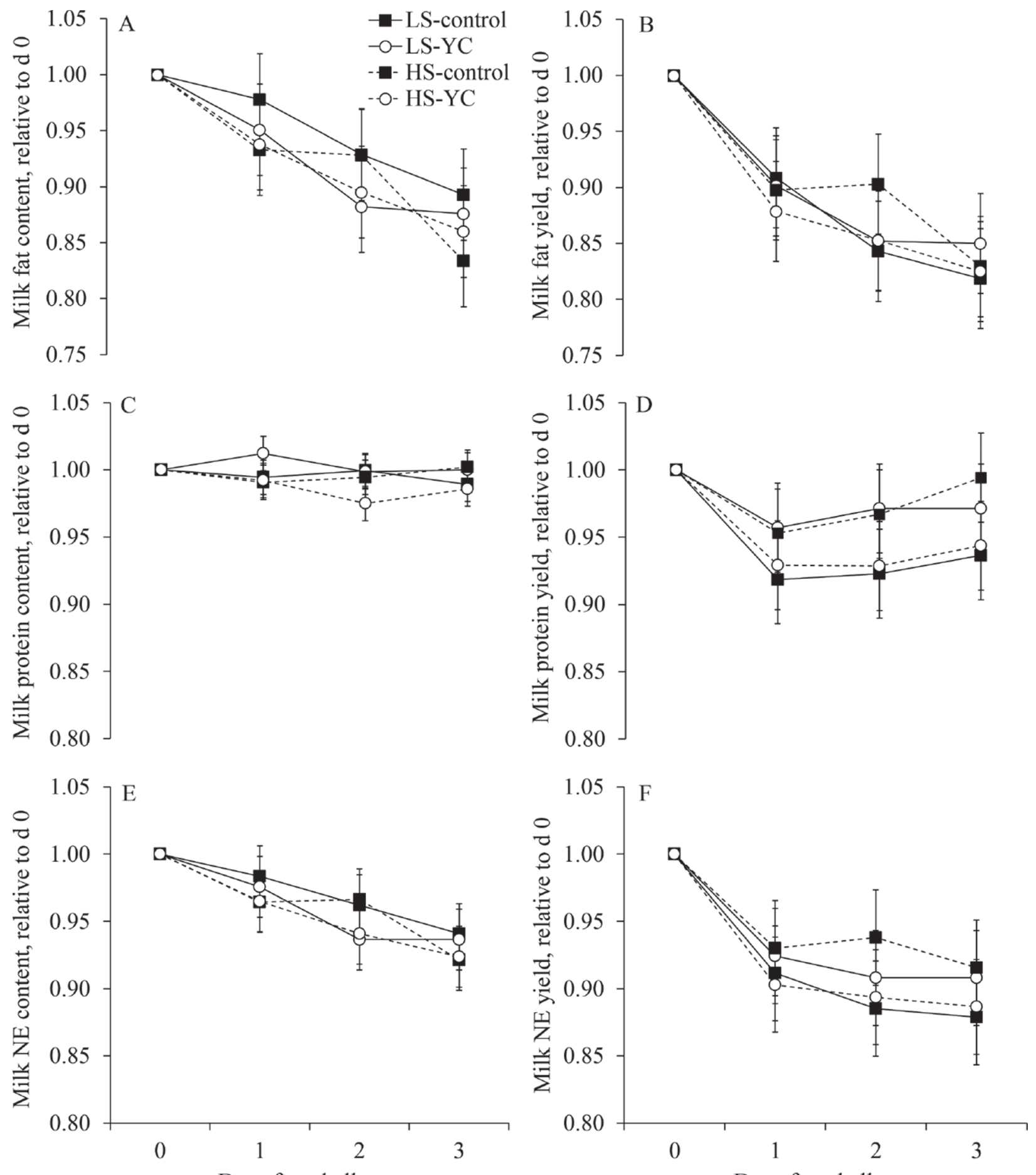

Day after challenge

Day after challenge

Figure 3. Relative changes in content and yield of milk components after a challenge with $3 \mathrm{~kg}$ of corn DM on d 0 in cows fed diets containing either 23 (LS) or $29 \%$ (HS) starch and not supplemented (control) or supplemented with $15 \mathrm{~g} / \mathrm{d}$ yeast culture (YC). Day 0 represents the mean value of the $2 \mathrm{~d}$ preceding the challenge. Panel A, milk fat content; effects of level of starch $(P=0.34), \mathrm{YC}(P=0.14)$, and interaction between level of starch and YC $(P=0.43)$. Panel B, milk fat yield; effects of level of starch $(P=0.95)$, YC $(P=0.84)$, and interaction between level of starch and YC $(P=0.59)$. Panel C, milk protein content; effects of level of starch $(P=0.36)$, YC $(P=0.91)$, and interaction between level of starch and YC $(P=0.29)$. Panel D, milk protein yield; effects of level of starch $(P=0.83)$, YC $(P=0.96)$, and interaction between level of starch and YC $(P=0.19)$. Panel E, milk net energy (NE) content; effects of level of starch $(P=0.58)$, YC $(P=0.53)$, and interaction between level of starch and YC $(P=0.88)$. Panel F, milk NE yield; effects of level of starch $(P=0.75)$, YC $(P=0.83)$, and interaction between level of starch and YC $(P=0.31)$. Error bars represent SEM (A, SEM =0.040; B, SEM =0.045; C, SEM =0.013; D, SEM =0.033; E, SEM $=0.023 ; \mathrm{F}, \mathrm{SEM}=0.035$ ) 
rumen were high after the morning feeding and likely declined overtime. Poppy et al. (2012) reviewed the literature on yeast culture and out of 35 experiments with reported method of delivery, 12 used top-dressing as the means to deliver the yeast culture to dairy cows. In the database, 33 treatment comparisons used yeast culture mixed with the TMR, whereas 19 treatment comparisons used top-dressing. The authors demonstrated that both delivery methods improved milk yield compared with untreated controls, although the magnitude of effect was larger for top-dressing than mixing with the TMR, with top dressing showing heterogeneity in response (Poppy et al., 2012).

Altering the starch content in the ration resulted in major changes in feeding behavior in dairy cows. Increasing starch depressed DMI during the 2-d observation period, but supplementing $\mathrm{YC}$ abolished the intake depression observed in the HS diet. The HS diet reduced meal size, meal duration, and total time eating. Digestion of starch favors increased propionate concentrations in the rumen and propionate is an important hypophagic compound in ruminants (Allen et al., 2009). Allen et al. (2009) proposed that increased portal flux of propionate and uptake by the liver often observed after a meal (Benson et al., 2002) increases hepatic oxidative reactions that induce satiety resulting in shorter meals (Oba and Allen, 2003). The smaller meal resulted in a shorter intermeal interval and increased eating rate, which might further reduce rumen $\mathrm{pH}$ and affect rumen fiber digestion. Perhaps the anorexigenic effects of propionate combined with less rumen fiber digestion shown by Dias et al. (2018) explain the reduced DMI in cows fed HS-control. On the other hand, supplementing $\mathrm{YC}$ to the HS diet attenuated this response and resulted in similar DMI to those fed the LS diet. An alternative explanation for increased rumen $\mathrm{pH}$ or improved rumen function proposed by Allen and Ying (2012) is that supplementation with yeast culture reduced the rate of starch digestion in the rumen in cows with greater DMI, therefore benefiting high-producing cows. Dias et al. (2018) showed a tendency for interaction between level of dietary starch and supplemental YC for rumen starch digestion. Feeding YC did not influence rumen starch digestion in cows fed LS, but it reduced rumen starch digestion in cows fed the HS diet (Dias et al., 2018). It is possible that the reduced rate of rumen starch digestion by yeast culture proposed by Allen and Ying (2012) might have reduced the satiety effects of the HS when cows were fed HS-YC.

Challenging cows with finely ground corn reduced milk fat content and yield, which reduced the NE secreted as milk in the $3 \mathrm{~d}$ following the challenge. Fat yield decreased $17 \%$ by d 3 after the challenge and all treatments showed the same relative loss of milk fat yield. Because the challenge induced a transient reduction in DMI and a marked depression in the fat content of milk, it is not surprising that the NE secretion as milk declined $10 \%$ in the days following the challenge. Supplementing YC did not influence the depression in milk fat and loss of milk NE secretion in dairy cows, although it prevented the decline in rumen $\mathrm{pH}$ in cows fed HS after the grain challenge. Longuski et al. (2009) replaced dry ground corn with finely ground highmoisture corn to induce a period of increased production of fermentation acids. The authors showed that the challenge with more fermentable starch reduced DMI and yield of milk fat; however, the loss in milk fat yield was prevented by supplementing the diets with yeast culture. In the current experiment, YC was unable to prevent the loss in milk fat yield, perhaps because it did not prevent the sudden changes in rumen fermentation to influence fat synthesis by the mammary gland. In the days preceding the challenge, cows were consuming $27 \mathrm{~kg}$ of $\mathrm{DM} / \mathrm{d}$ and intake decreased to an average of $25.7 \mathrm{~kg} / \mathrm{d}$ on the day of challenge. The $3 \mathrm{~kg}$ of corn grain (2.2 kg of corn starch) increased the starch contents in the diet consumed by cows on the day of challenge from 23 to $28.9 \%$ in LS and from 29 to $34.2 \%$ in the HS diet. The sudden increase in starch intakes in LS, from 6.2 to $7.4 \mathrm{~kg} / \mathrm{d}$, and HS, from 7.8 to $8.8 \mathrm{~kg} / \mathrm{d}$, might have precluded any potential effects of $\mathrm{YC}$ on milk fat depression. Another option is that the YC used simply improves yields of FCM and ECM by stimulating digestion and intake, but not by preventing changes in milk composition as observed by others (Longuski et al., 2009). In fact, milk fat content did not change throughout the experiment in cows fed YC.

The HS diet increased SCFA concentrations in rumen fluid, and the effect of altering dietary starch on rumen fermentation is well documented. Increasing dietary content of fermentable carbohydrates usually increases SCFA concentrations and reduces rumen $\mathrm{pH}$ (Oba and Allen, 2003; Agle et al., 2010). Cows fed HS$\mathrm{YC}$ had greater rumen $\mathrm{pH}$ than those fed HS-control, which might have been caused by the positive effects of $\mathrm{YC}$ on stimulating microorganisms that use lactic acid as substrate, resulting in a more stable rumen environment (Nisbet and Martin, 1991; Callaway and Martin, 1997). Lactate concentrations decreased in cows fed YC and the reduction was greater in those fed the HS than the LS diet. Feeding steers yeast culture attenuated the postprandial concentrations of lactate in a diet containing 50\% hay and 50\% barley grain (Williams et al., 1991). Also, feeding live yeast products has been shown to reduce the risk of ruminal acidosis (Bach et al., 2007; AlZahal et al., 2014), which would be appropriate for diets with low forage NDF and high starch content. In the current experiment, feeding YC reduced lactate content 
in the rumen fluid and increased rumen $\mathrm{pH}$ in cows fed HS after the challenge with corn grain. Similarly, Dias et al. (2018) observed that supplementing YC increased rumen $\mathrm{pH}$ and reduced the minutes with $\mathrm{pH}$ below 6.0 in cows fed HS. AlZahal et al. (2014) subjected cows to high-grain/high-starch feeding and showed that supplementing diets with a live yeast product attenuated the depression in rumen $\mathrm{pH}$ and improved productive performance. Bach et al. (2007) suggested that one of the mechanisms by which live yeast increases rumen $\mathrm{pH}$ and reduces the risk of subacute rumen acidosis is by altering patterns of feed intake and feeding behavior in cows receiving TMR and additional concentrates during milking, which could favor a more stable rumen fermentation. Nevertheless, changes in feeding behavior have not always been observed with supplemental live yeast or yeast culture. Cows fed TMR containing 30\% NDF showed increased total-tract NDF digestion and improved yields of milk components without changes in feeding behavior when fed live yeast (Bitencourt et al., 2011). Also, supplementing diets with YC in the current experiment seemed to have minor effects on feeding behavior, which were observed primarily in cows fed the LS diet and, therefore, less prone to rumen acidosis.

The concentration of plasma haptoglobin in the first 5 wk of the experiment tended to be reduced by feeding YC. Furthermore, YC reduced plasma haptoglobin in cows fed HS after the grain challenge. Haptoglobin is an acute phase protein synthesized by hepatocytes in response to release of cytokines from immune cells following an inflammatory insult (Murata et al., 2004). Changes in rumen fermentation after induction of acidosis increases LPS in the rumen fluid that induce an acute phase response (Plaizier et al., 2008). It is possible that the positive effect of $\mathrm{YC}$ on rumen $\mathrm{pH}$ and lactate concentrations of cows fed HS might have attenuated a potential insult that could have induced haptoglobin release by the liver. Similar findings were also observed by Dias et al. (2018).

Concentrations of glucose increased and those of urea $\mathrm{N}$ decreased in cows fed the HS compared with the LS diet. Feeding HS stimulated propionate concentrations in the rumen, which is likely to favor gluconeogenesis and increase glucose concentrations (Huntington et al., 2006). Also, during the challenge, cows fed the HS diet had attenuated increase in plasma concentrations of nonesterified fatty acids, likely as a result of the increase glucose and reduced lipolysis. The smaller concentration of urea $\mathrm{N}$ with feeding HS compared with LS was probably caused by the improved gut $\mathrm{N}$ recycling and capture as microbial $\mathrm{N}$, which is observed in high rumen-fermentable diets (Lapierre and Lobley, 2001). In fact, feeding $\mathrm{HS}$ tended to reduce rumen $\mathrm{NH}_{3}-\mathrm{N}$ concentrations in all cows and increased microbial protein yield in dairy cows supplemented with YC (Dias et al., 2018).

\section{CONCLUSIONS}

Supplementing diets of dairy cows with yeast culture increased yields of 3.5\% FCM and ECM and the increments were observed in both low- and high-starch diets. Despite increases in yield of ECM, treatment did not influence NE balance. Feeding the high starch diet tended to increase milk yield and increased the yield of milk true protein, but did not affect fat yield or yields of FCM or ECM. Altering the dietary starch content influenced feeding behavior of dairy cows by reducing meal size, eating time, and intermeal interval, and increased eating rate. After a challenge with corn grain, feeding yeast culture attenuated the depression in rumen $\mathrm{pH}$ and reduced concentrations of lactate in rumen fluid and haptoglobin in plasma of cows fed the highstarch diet, suggesting a reduced risk for subacute rumen acidosis. Feeding yeast culture improved lactation performance irrespective of the level of dietary starch, and it reduced the risk of subacute rumen acidosis after a grain challenge in cows fed a high-starch ration.

\section{ACKNOWLEDGMENTS}

The authors thank Gabriel Gomes, Marcos Zenobi, Natalia Martinez, Eduardo Ribeiro, Rafael Bisinotto, Sergei Senikov, Pedro Monteiro Jr., Raylon P. Maciel, Thiago V. Silva, and the staff of the University of Florida Dairy Unit for assistance with the experiment. Funding for this experiment was provided by a grant from ICC Brazil, São Paulo, Brazil. José A. Freitas was supported by the postdoctorate fellowship protocol \#209276/2012-6 from the Brazilian National Council for Scientific and Technological Development (CNPq). The senior author, André L.G. Dias, was supported by the fellowship Science without Borders \#246544/20120 from CNPq, Brazil.

\section{REFERENCES}

Agle, M., A. N. Hristov, S. Zaman, C. Schneider, P. M. Ndegwa, and V. K. Vaddella. 2010. Effect of dietary concentrate on rumen fermentation, digestibility, and nitrogen losses in dairy cows. J. Dairy Sci. 93:4211-4222.

Allen, M. S., B. J. Bradford, and M. Oba. 2009. Board invited review: The hepatic oxidation theory of the control of feed intake and its application to ruminants. J. Anim. Sci. 87:3317-3334.

Allen, M. S., and Y. Ying. 2012. Effects of Saccharomyces cerevisiae fermentation product on ruminal starch digestion are dependent upon dry matter intake for lactating cows. J. Dairy Sci. 95:65916605.

AlZahal, O., L. Dionissopoulos, A. H. Laarman, N. Walker, and B. W. McBride. 2014. Active dry Saccharomyces cerevisiae can alleviate 
the effect of subacute ruminal acidosis in lactating dairy cows. J. Dairy Sci. 97:7751-7763.

Bach, A., C. Iglesias, and M. Devant. 2007. Daily rumen pH pattern of loose-housed dairy cattle as affected by feeding pattern and live yeast supplementation. Anim. Feed Sci. Technol. 136:146-153.

Baker, S., and T. Herrman. 2002. Evaluating particle size. MF-2051. Kansas State Univ., Manhattan.

Benson, J. A., C. K. Reynolds, P. C. Aikman, B. Lupoli, and D. E. Beever. 2002. Effects of abomasal vegetable oil infusion on splanchnic nutrient metabolism in lactating dairy cows. J. Dairy Sci. 85:1804-1814.

Bitencourt, L. L., J. R. M. Silva, B. M. L. Oliveira, G. S. Dias Jr., F. Lopes, S. Siecola Jr., O. F. Zacaroni, and M. N. Pereira. 2011. Diet digestibility and performance of dairy cows supplemented with live yeast. Sci. Agric. 68:301-307.

Box, G. E., and D. R. Cox. 1964. An analysis of transformations. J. R. Stat. Soc. B 26:211-252.

Bruno, R. G. S., H. Rutigliano, R. L. Cerri, P. H. Robinson, and J. E. P. Santos. 2009. Effect of feeding yeast culture on performance of dairy cows during summer heat stress. Anim. Feed Sci. Technol. 150:175-186.

Callaway, E. S., and S. A. Martin. 1997. Effects of a Saccharomyces cerevisiae culture on ruminal bacteria that utilize lactate and digest cellulose. J. Dairy Sci. 80:2035-2044

Canale, A., M. E. Valente, and A. Ciotti. 1984. Determination of volatile carboxylic acids (C1-C5) and lactic acid in aqueous acid extracts of silage by high-performance liquid chromatography. J. Sci. Food Agric. 35:1178-1182.

Chaucheyras-Durand, F., and G. Fonty. 2001. Establishment of cellulolytic bacteria and development of fermentative activities in the rumen of gnotobiotically-reared lambs receiving the microbial additive Saccharomyces cerevisiae CNCM I-1077. Reprod. Nutr. Dev. 41:57-68.

Desnoyers, M., S. Giger-Reverdin, G. Bertin, C. Duvaux-Ponter, and D. Sauvant. 2009. Meta-analysis of the influence of Saccharomyces cerevisiae supplementation on ruminal parameters and milk production of ruminants. J. Dairy Sci. 92:1620-1632.

Dias, A. G., J. A. Freitas, B. Micai, L. F. Greco, and J. E. P. Santos, 2018. Effect of supplemental yeast culture and dietary starch content on rumen fermentation and digestion in dairy cows. J. Dairy Sci. 101:201-221. https://doi.org/10.3168/jds.2017-13241.

Ferguson, J. D., D. T. Galligan, and N. Thomsen. 1994. Principal descriptors of body condition score in Holstein cows. J. Dairy Sci. $77: 2695-2703$

Gochman, N., and J. M. Schmitz. 1972. Application of a new peroxide indicator reaction to the specific, automated determination of glucose with glucose oxidase. Clin. Chem. 18:943-950.

Harrison, G. A., R. W. Hemken, K. A. Dawson, R. J. Harmon, and B. K. Barker. 1988. Influence of addition of yeast culture supplement to diets of lactating cows on ruminal fermentation and microbial population. J. Dairy Sci. 71:2967-2975.

Huntington, G. B., D. L. Harmon, and C. J. Richards. 2006. Sites, rates, and limits of starch digestion and glucose metabolism in growing cattle. J. Anim. Sci. 84:E14-E24.

Johnson, M. M., and J. P. Peters. 1993. Technical note: An improved method to quantify nonesterified fatty acids in bovine plasma. J. Anim. Sci. 71:753-756.

Jørgensen, E., and A. R. Pedersen. 1998. How to obtain those nasty standard errors from transformed data-And why they should not be used. Biometry Research Unit - Internal report 7. Danish Institute of Agricultural Sciences.

Karkalas, J. 1985. An improved enzymic method for the determination of native and modified starch. J. Sci. Food Agric. 36:1019-1027.
Lapierre, H., and G. E. Lobley. 2001. Nitrogen recycling in the ruminant: A review. J. Dairy Sci. 84(Suppl. 1):E223-E236.

Longuski, R. A., Y. Ying, and M. S. Allen. 2009. Yeast culture supplementation prevented milk fat depression by a short-term dietary challenge with fermentable starch. J. Dairy Sci. 92:160-167.

Makimura, S., and N. Suzuki. 1982. Quantitative determination of bovine serum haptoglobin and its elevation in some inflammatory diseases. Jpn. J. Vet. Sci. 44:15-21.

Maltz, E., L. F. Barbosa, P. Bueno, L. Scagion, K. Kaniyamattam, L. F. Greco, A. de Vries, and J. E. P. Santos. 2013. Effect of precision feeding on performance, nutrient excretion and feeding behavior of early lactation dairy cows. J. Dairy Sci. 96:5249-5266.

Marsh, W. H., B. Fingerhut, and H. Miller. 1965. Automated and manual direct methods for the determination of blood urea. Clin. Chem. 11:624-627.

Mullins, C. R., L. K. Mamedova, A. J. Carpenter, Y. Ying, M. S. Allen, I. Yoon, and B. J. Bradford. 2013. Analysis of rumen microbial populations in lactating dairy cattle fed diets varying in carbohydrate profiles and Saccharomyces cerevisiae fermentation product. J. Dairy Sci. 96:5872-5881.

Murata, H., N. Shimada, and M. Yoshioka. 2004. Current research on acute phase proteins in veterinary diagnosis: an overview. Vet. J. 168:28-40.

Nisbet, D. J., and S. A. Martin. 1991. Effect of a Saccharomyces cerevisiae culture on lactate utilization by the ruminal bacterium Selenomonas ruminantium. J. Anim. Sci. 69:4628-4633.

Nocek, J. E., M. G. Holt, and J. Oppy. 2011. Effects of supplementation with yeast culture and enzymatically hydrolyzed yeast on performance of early lactation dairy cattle. J. Dairy Sci. 94:40464056.

Noel, R. J., and L. G. Hambleton. 1976. Collaborative study of a semiautomated method for determination of crude protein in animal feeds. J. Assoc. Off. Anal. Chem. 59:134-140.

NRC. 2001. Nutrient Requirements of Dairy Cattle. 7th rev. ed. Natl. Acad. Sci., Washington, DC.

Oba, M., and M. S. Allen. 2003. Effects of corn grain conservation method on feeding behavior and productivity of lactating dairy cows at two dietary starch concentrations. J. Dairy Sci. 86:174183.

Plaizier, J. C., D. O. Krause, G. N. Gozho, and B. W. McBride. 2008 Subacute ruminal acidosis in dairy cows: The physiological causes, incidence and consequences. Vet. J. 176:21-31.

Poppy, G. D., A. R. Rabiee, I. J. Lean, W. K. Sanchez, K. L. Dorton, and P. S. Morley. 2012. A meta-analysis of the effects of feeding yeast culture produced by anaerobic fermentation of Saccharomyces cerevisiae on milk production of lactating dairy cows. J. Dairy Sci. 95:6027-6041.

Schingoethe, D. J., K. N. Linke, K. F. Kalscheur, A. R. Hippen, D. R. Rennich, and I. Yoon. 2004. Feed efficiency of mid-lactation dairy cows fed yeast culture during summer. J. Dairy Sci. 87:4178-4181.

Shaver, R. D., and J. E. Garrett. 1997. Effect of dietary yeast culture on milk yield, composition and component yields at commercial dairies. Prof. Anim. Sci. 13:204-207.

Van Soest, P. J., J. B. Robertson, and B. A. Lewis. 1991. Methods for dietary fiber, neutral detergent fiber, and nonstarch polysaccharides in relation to animal nutrition. J. Dairy Sci. 74:3583-3597.

Williams, P. E., C. A. Tait, G. M. Innes, and C. J. Newbold. 1991. Effects of the inclusion of yeast culture (Saccharomyces cerevisiae plus growth medium) in the diet of dairy cows on milk yield and forage degradation and fermentation patterns in the rumen of steers. J. Anim. Sci. 69:3016-3026. 